\title{
5-HTR2A and IL-6 polymorphisms and obstructive sleep apnea-hypopnea syndrome
}

\author{
WENJUAN WU, ZHIJUN LI, TINGYU TANG, JINYAN WU, FANG LIU and LIANG GU \\ Department of Respiratory, Zhejiang Hospital, Hangzhou, Zhejiang 310013, P.R. China
}

Received April 27, 2015; Accepted June 10, 2015

DOI: $10.3892 /$ br.2015.558

\begin{abstract}
At present, variants of the 5-hydroxytryptamine receptor $2 \mathrm{~A}(5-H T R 2 A)$ and interleukin-6 (IL-6) genes may be susceptible markers to develop for obstructive sleep apnea-hypopnea syndrome (OSAHS). Therefore, the aim of the present study was to explore the potential associations between the 5-HTR2A and IL- 6 single-nucleotide polymorphisms (SNPs) and OSAHS. In total there were 130 cases and 136 controls collected for genotyping of 5-HTR $2 A$ (rs6311) and $I L-6$ (rs1800796) SNPs. The association of these SNPs with OSAHS risk were evaluated by computing the odds ratio (OR) and $95 \%$ confidence interval (CI) from multivariate unconditional logistic regression analyses with adjustment for gender and age. The results indicated that the genotype and allele frequencies in these two loci (rs6311 and rs1800796) were not significantly different between the cases and controls. However, carrying the ' $\mathrm{C}$ ' allele of rs6311 has a protective effect against OSAHS via the gender-specific comparison ( $\mathrm{P}=0.0409$; OR, 1.744; 95\% CI, 1.021-2.978). The ' $G$ ' allele and ' $C G$ ' genotype distribution of rs1800796, and ' $\mathrm{C}$ ' allele and ' $\mathrm{CT}$ ' genotype distribution of rs6311 have significant differences between the mild and moderate group $(\mathrm{P}<0.05)$. Similarly, the genotype distribution of rs6311 has differences between mild and severe cases $(\mathrm{P}=0.0026)$. The current research demonstrated that variants of rs6311 have an association with OSAHS in males. Additionally, polymorphisms of rs6311 and rs1800796 have relevance to the severity of OSAHS.
\end{abstract}

Correspondence to: Dr Zhijun Li, Department of Respiratory, Zhejiang Hospital, 12 Lingyin Road, Hangzhou, Zhejiang 310013, P.R. China

E-mail: 1zj13575748493@sina.com

Key words: interleukin-6, 5-hydroxytryptamine receptor 2A, obstructive sleep apnea-hypopnea syndrome, single-nucleotide polymorphisms

\section{Introduction}

Obstructive sleep apnea-hypopnea syndrome (OSAHS), due to the reduction or complete cessation in airflow, resulted in recurrent hypoxia and hypercapnia, and chronic excessive daytime sleepiness, increased risk of hypertension, coronary artery disease, congestive heart failure, stroke, cardiac arrhythmias and sudden cardiac fatality. OSAHS involves a collapsible upper airway that is dependent upon dilator muscles for patency and normal respiration. The prevalence is increasing worldwide, and may be a major public health issue, estimated to affect $6-13 \%$ of the adult popultion in Western society (1).

At present, the pathogenesis of OSAHS is not fully understood at the molecular level. Certain genetic and epidemiological studies have demonstrated that the risk of OSAHS is associated with multiple genes (2), such as 5-hydroxytryptamine receptor $(5-H T R)$ and inflammatory factor interleukin-6 $(I L-6)$ genes. Genetic variants contribute to an increase in the susceptibility to OSAHS through four possible pathogenic pathways, including upper airway anatomy and craniofacial form, ventilation control and upper airway collapsibility, body fat distribution and sleep-wake controlling (3).

Serotonergic neurons that are innervating motoneurons increase the response to respiratory challenges. 5-HT regulates physiological activity via 5-HTR, and 5-HTR2A is the predominant excitatory 5-HTR subtype at the hypoglossal motor neurons (4). This subtype has an important role in the maintenance of upper airway stability and normal breathing. Serotonin delivery is reduced to upper airway dilator motor neurons in sleep and it contributes, at least in part, to sleep-related reductions in dilator muscle activity and upper airway obstruction (5), which suggests this characterization of serotonin receptor subtypes in the hypoglossal nucleus provides a focus for the development of pharmacotherapies for sleep apnea. The polymorphism of the genes that code for 5-HTR alter its transcription, affecting the number of receptors in the serotoninergic system, and may increase the risk of OSAHS. Recently, 3 meta-analyses (6-8) revealed that no differences were observed in the prevalence of T102C (rs6311) polymorphisms in the case and control groups $(\mathrm{P}>0.05)$. However, the $-1438 \mathrm{G}-\mathrm{A}$ polymorphism in the $5-H T R 2 A$ gene was significantly correlated with the increased risk of OSAHS, showing that the ' $\mathrm{T}$ ' and ' $\mathrm{C}$ ' allele are not involved in OSAHS. 
Table I. Oligonucleotide sequences used for genotyping.

\begin{tabular}{llll}
\hline Gene & SNPs & Primers & Sequences \\
\hline $5-H T R 2 A$ & rs6311 & First & 5'-ACGTTGGATGGGCTAGAAAACAGTATGTCC-3' \\
& & Second & 5'-ACGTTGGATGTGGACACAAACACTGTTGGC-3' \\
& & Extension & 5'-GGAGTGCTGTGAGTGTC-3' \\
$I L-6$ & rs1800796 & First & 5'-ACGTTGGATGTGGAGACGCCTTGAAGTAAC-3' \\
& & Second & 5'-ACGTTGGATGTCTTCTGTGTTCTGGCTCTC-3' \\
& & Extension & 5'-GGAATGCAGTTCTACAACAGCC-3' \\
\hline
\end{tabular}

5-HT2AR, 5-hydroxytryptamine receptor 2A; IL-6, interleukin-6.

Intense local and systemic inflammation are present in patients, and this process may promote oropharyngeal inspiratory muscle dysfunction and amplify upper airway narrowing and collapsibility, worsening the frequency and duration of sleep apnea (9). Therefore, inflammation may contribute to upper airway pathophysiology and OSAHS is usually associated with increasing levels of inflammatory cytokines (10-12). At present, a previous study revealed the correlation between the polymorphism located in the promoter region of the inflammatory cytokine genes and OSAHS (13). IL-6 is a circulating cytokine, known to be secreted from a number of different cells, including activated macrophages and lymphocytes. Evidence has demonstrated that the plasma levels of pro-inflammatory cytokines, such as IL-6, are observed to be elevated in OSAHS patients, are associated with the severity of disease (12) and are significantly reduced following continuous positive airway pressure therapy (14). It appears reasonable to hypothesize that abnormalities in the $I L-6$ gene could be relevant to the etiology of OSAHS. Larkin et al (15) reported that one single-nucleotide polymorphism (SNP) of the $I L-6$ gene was associated with protecting against OSAHS following adjusting for body mass index (BMI) [odds ratio (OR) for ' $\mathrm{T}$ ' allele, 0.24 ; 95\% confidence interval (CI), 0.09-0.67; $\mathrm{P}=0.006$ ), which suggests that variants in $I L-6$ may influence the risk of OSAHS independent of obesity.

Based on these findings, genetic susceptibility was one possible factor influencing this disparity. Therefore, the present study investigated the susceptibility of 5-HTR2A and IL-6 genes for OSAHS development, and a matched case-control study was conducted to examine whether or not this association resided in the Chinese Han population.

\section{Materials and methods}

Subjects. The patients were Chinese Han individuals living in Southeast China and were enrolled from the Sleep Laboratory, Department of Respiratory, Zhejiang Hospital (Zhejiang, China) between March 2013 and December 2013. Controls were negative personal and family history of sleep disorder that enrolled from the same region. All the subjects provided informed consent and received an overnight polysomnography prior to classfication into cases or controls. All the subjects were divided into two subgroups according to BMI: Overweight BMI, $\geq 25 \mathrm{~kg} / \mathrm{m}^{2}$ and normal weight BMI, $<25 \mathrm{~kg} / \mathrm{m}^{2}$. The research was approved by the Ethics Committee of Zhejiang Hospital.
Polysomnography. The participants were diagnosed based on overnight polysomnography (Alice LE; Philips Respironics, Inc., Murrysville, PA, USA), comprising of pulsoxymetry, electrophysiological signals (electroencephalography, electrooculogram, electromyography and electrocardiography) and sleep phases, thoracic movement observation, analysis of sleep stages and snoring phases, and awakening reactions. Two sleep specialists reviewed the recordings independently. Apnea was referred to as the continuous cessation of airflow $>10 \mathrm{sec}$ and hypopnea was defined as $\geq 50 \%$ of reduction in airflow $>10 \mathrm{sec}$ with oxygen desaturation of $\geq 4 \%$. The apnea-hypopnea index (AHI) was calculated as the total number of apneas + hypopneas/h. As for severity of OSAHS, patients were grouped according to the following classification: Mild (AHI from 5 to 15 events/h), moderate (AHI from 16 to 30 events/h) and severe OSAHS (AHI $>30$ events/h).

DNA extraction and genotyping. Whole blood samples were obtained the morning after the polysomnogram and were stored at $-70^{\circ} \mathrm{C}$. DNA was isolated from blood samples using the AxyPrep Blood Genomic DNA Miniprep kit (Axygen Biosciences, Union City, CA, USA) from peripheral leucocytes genome. The polymorphisms of the 5-HTR2A and IL-6 genes were amplified by polymerase chain reaction (PCR) using the GeneAmp PCR System 9700 (ABI Co., Ltd., USA). Primers for PCR and single-base extension were designed using the Assay Designers software version 3.0 (Sequenom Inc., San Diego, CA, USA) and were processed following standard protocols for iPLEX chemistry. Primers were synthesized by Sangon Biotech Shanghai Co., Ltd. (Shanghai, China; Table I).

Multiplex PCR was performed in $5 \mu \mathrm{l}$ volumes containing 0.1 units of HotStarTaq polymerase (Qiagen, Hilden, Germany), $10 \mathrm{ng}$ of whole-genome-amplified genomic DNA, $2.5 \mathrm{pmol}$ of each PCR primer and $2.5 \mu \mathrm{mol}$ of deoxyribonucleotide (dNTP). Thermocycling was at $94^{\circ} \mathrm{C}$ for 15 min followed by 45 cycles at $94^{\circ} \mathrm{C}$ for $20 \mathrm{sec}, 56^{\circ} \mathrm{C}$ for $30 \mathrm{sec}$ and $72^{\circ} \mathrm{C}$ for $1 \mathrm{~min}$, and a final incubation at $72^{\circ} \mathrm{C}$ for $3 \mathrm{~min}$. Unincorporated dNTPs were deactivated using 0.3 units of shrimp alkaline phosphatase (Sequenom Inc.) followed by primer extension using $5.4 \mathrm{pmol}$ of each primer extension probe, $50 \mu \mathrm{mol}$ of the appropriate dNTP combination and 0.5 units of iPLEX enzyme (Sequenom Inc.). The extension reactions were carried out at $94^{\circ} \mathrm{C}$ for $30 \mathrm{sec}$ and subsequently $94^{\circ} \mathrm{C}$ for $5 \mathrm{sec}$, followed by 5 cycles at $52^{\circ} \mathrm{C}$ for $5 \mathrm{sec}$ and $80^{\circ} \mathrm{C}$ for $5 \mathrm{sec}$, for a total of 40 cycles, and finally $72^{\circ} \mathrm{C}$ for $3 \mathrm{~min}$. A cation-exchange resin 
was used to remove residual salt from the reactions. Purified primer extension reaction products were spotted onto a 384-well SpectroChip using the MassARRAY Nanodispenser and determined by the matrix assisted laser desorptionization time-of-flight mass spectrometer. Genotype calling was performed in real-time (RT) with MassARRAY RT software version 3.0.0.4 and analyzed using the MassARRAY Typer software version 3.4 .

Statistical analysis. Calculations of allele and genotype frequency, and tests of Hardy-Weinberg equilibrium (HWE) were performed using Microsoft Excel macro PHARE version 2.1. Comparion of the allele and genotypes in cases versus controls was carried out using Pearson's $\chi^{2}$ tests. OR and $95 \% \mathrm{CI}$ were obtained with Plink software. $\mathrm{P}<0.05$ was considered to indicate a statistically significant difference. Statistical powers were calculated using software of Power for Association with Error (PAWE version 1.2; Chad Haynes Laboratory of Statistical Genetics, The Rockefeller University, New York, NY, USA).

\section{Results}

General characteristics of studies. The characteristic data of samples are shown in Table II. In total there were 130 OSAHS patients (20 females and 110 males) and 136 healthy controls (24 females and 112 males) of Chinese Han origin. The mean age in cases and controls was 51.78 years (range, 31-67 years) and 50.88 years (range, 31-60 years), respectively. The controls were matched with cases by gender and age. BMI in the patient group was predominantly overweight, constituting 116 $(89.23 \%)$ cases, whereas $44(32.35 \%)$ of the control group were normal or lose weight $(\mathrm{P}=0.005)$. The studied population was from HWE with the P-values of 0.42495 in rs6311 and 0.96779 in rs1800796, respectively, indicating that there was no evidence of deviation (Table III).

Gene polymorphisms in case and control cohorts. For 5-HTR $2 A$ gene polymorphisms, there was no difference between the genotypes and allele frequencies of the patients
Table II. Demographic data of the OSAHS and control groups.

\begin{tabular}{lcrr}
\hline Variables & Patients & Controls & P-value \\
\hline Gender, n (\%) & & & \\
Male & $110(84.6)$ & $112(82.4)$ & 0.817 \\
Female & $20(15.4)$ & $24(17.6)$ & \\
Age, years & $51.78 \pm 12.24$ & $50.88 \pm 8.21$ & 0.617 \\
BMI, kg/m ${ }^{2}$ & $28.17 \pm 3.62$ & $25.38 \pm 3.17$ & \\
Weight, n (\%) & & & \\
Normal & $14(10.8)$ & $44(32.4)$ & 0.005 \\
Overweight & $116(89.2)$ & $92(67.7)$ & \\
AHI, n $(\%)$ & & & \\
Mild & $26(20.0)$ & $\mathrm{UN}$ & \\
Moderate & $22(16.9)$ & $\mathrm{UN}$ & \\
Severe & $82(63.1)$ & $\mathrm{UN}$ & \\
\end{tabular}

Data are mean \pm standard deviation. OSAHS, obstructive sleep apnea-hypopnea syndrome; BMI, body mass index; AHI, apnea-hypopnea index; UN, unknown.

Table III. HWE Pearson's P-value in cases and controls.

\begin{tabular}{llc}
\hline Gene & \multicolumn{1}{c}{ rs } & HWE Pearson's P-value \\
\hline $5-H T 2 A R$ & rs6311 & 0.42495 \\
$I L-6$ & rs1800796 & 0.96779 \\
\hline
\end{tabular}

HWE, Hardy-Weinberg equilibrium; 5-HT2AR, 5-hydroxytryptamine receptor $2 \mathrm{~A}$; IL-6, interleukin-6.

and controls ( $\mathrm{P}>0.05$ ) (Table IV). However, for male OSAHS patients and controls, the allele frequencies of rs6311 were $60.2 \%(\mathrm{~T})$ and $39.8 \%(\mathrm{C})$ in the cases, and $46.4 \%(\mathrm{~T})$ and $53.6 \%(\mathrm{C})$ in the controls, and the difference between the two groups was statistically significant $(\mathrm{P}=0.0409$; OR, 1.744; 95\% CI, 1.021-2.978) (Table V), which suggests that males carrying the ' $\mathrm{T}$ ' allele of rs6311 have a 1.744-fold chance

Table IV. Allele and genotype distribution in patient and control groups and their association with OSAHS risk.

\begin{tabular}{|c|c|c|c|c|c|}
\hline Gene & Cases, n (\%) & Controls, n (\%) & $\chi^{2}$ test & P-value & OR $(95 \%$ CI $)$ \\
\hline \multicolumn{6}{|c|}{ 5-HTR2A rs6311 } \\
\hline $\mathrm{T}$ & $155(60.5)$ & $133(48.9)$ & & & \\
\hline $\mathrm{C}$ & $101(39.5)$ & $139(51.1)$ & 3.1549 & 0.0757 & $1.555(0.954-2.533)$ \\
\hline $\mathrm{CC}$ & $19(14.8)$ & $31(22.8)$ & & & \\
\hline TT & $44(34.4)$ & $31(22.8)$ & & & \\
\hline $\mathrm{CT}$ & $65(50.8)$ & $74(54.4)$ & 3.3948 & 0.1832 & \\
\hline \multicolumn{6}{|c|}{ IL-6 rs1800796 } \\
\hline $\mathrm{C}$ & 195 (75.6) & $188(69.1)$ & & & \\
\hline G & $63(24.4)$ & 84 (30.9) & 1.4636 & 0.2264 & $1.398(0.812-2.409)$ \\
\hline $\mathrm{CC}$ & $71(55.0)$ & $65(50.0)$ & & & \\
\hline GG & $9(7.0)$ & $11(8.5)$ & & & \\
\hline CG & $49(38.0)$ & $60(44.1)$ & 1.5671 & 0.4568 & \\
\hline
\end{tabular}


Table V. Allele and genotype distributions in the patient and control groups for gender-specific analysis.

\begin{tabular}{|c|c|c|c|c|c|c|c|c|}
\hline \multirow[b]{2}{*}{ Gene } & \multicolumn{2}{|c|}{ Male, n (\%) } & \multirow[b]{2}{*}{ P-value } & \multirow[b]{2}{*}{ OR $(95 \% \mathrm{CI})$} & \multicolumn{2}{|c|}{ Female, n $(\%)$} & \multirow[b]{2}{*}{$\mathrm{P}$-value } & \multirow[b]{2}{*}{ OR $(95 \% \mathrm{CI})$} \\
\hline & Cases & Control & & & Cases & Control & & \\
\hline \multicolumn{9}{|c|}{ 5-HTR2A rs6311 } \\
\hline $\mathrm{T}$ & $130(60.2)$ & $104(46.4)$ & & & $23(57.5)$ & $29(60.4)$ & & \\
\hline $\mathrm{C}$ & $86(39.8)$ & $120(53.6)$ & 0.0409 & $1.744(1.021-2.978)$ & $17(42.5)$ & 19 (49.6) & 0.8653 & $0.900(0.266-3.042)$ \\
\hline $\mathrm{CC}$ & $16(14.8)$ & $32(28.6)$ & & & $2(10.0)$ & $1(4.2)$ & & \\
\hline TT & $38(35.2)$ & $24(21.4)$ & & & $5(25.0)$ & $6(25.0)$ & & \\
\hline $\mathrm{CT}$ & $54(50.0)$ & $56(50.0)$ & 0.1206 & & $13(65.0)$ & $17(70.8)$ & 0.4892 & \\
\hline \multicolumn{9}{|c|}{$I L-6 \mathrm{rs} 1800796$} \\
\hline $\mathrm{C}$ & $165(75.0)$ & $155(69.2)$ & & & $28(77.8)$ & $35(72.9)$ & & \\
\hline $\mathrm{G}$ & $55(25.0)$ & $69(30.5)$ & 0.2093 & $1.456(0.809-2.622)$ & $8(22.2)$ & $13(27.1)$ & 0.8343 & $1.167(0.275-4.950)$ \\
\hline $\mathrm{CC}$ & $61(55.4)$ & $55(50.0)$ & & & $12(66.7)$ & $12(50.0)$ & & \\
\hline CG & $41(37.3)$ & $45(40.9)$ & & & $5(27.8)$ & $12(50.0)$ & & \\
\hline GG & $8(7.3)$ & $10(9.1)$ & 0.4427 & & $1(5.6)$ & $0(0.0)$ & 0.2692 & \\
\hline
\end{tabular}

OR, odds ratio; CI, confidence interval; 5-HT2AR, 5-hydroxytryptamine receptor 2A; IL-6, interleukin-6.

Table VI. Allele and genotype distributions in the patient and control groups according to weight.

\begin{tabular}{|c|c|c|c|c|c|c|c|c|}
\hline \multirow[b]{2}{*}{ Gene } & \multicolumn{2}{|c|}{ Normal weight, n (\%) } & \multirow[b]{2}{*}{ P-value } & \multirow[b]{2}{*}{ OR $(95 \% \mathrm{CI})$} & \multicolumn{2}{|c|}{ Overweight, n (\%) } & \multirow[b]{2}{*}{ P-value } & \multirow[b]{2}{*}{ OR $(95 \% \mathrm{CI})$} \\
\hline & Cases & Control & & & Cases & Control & & \\
\hline \multicolumn{9}{|c|}{ 5-HTR2A rs6311 } \\
\hline $\mathrm{T}$ & $21(75.0)$ & $47(56.0)$ & & & $130(56.5)$ & $85(46.2)$ & & \\
\hline $\mathrm{C}$ & $7(25.0)$ & $37(44.0)$ & 0.1142 & $3.029(0.737-12.455)$ & $100(43.5)$ & $99(53.8)$ & 0.0803 & $1.637(0.941-2.848)$ \\
\hline $\mathrm{CC}$ & $1(7.1)$ & $7(16.7)$ & & & $20(17.4)$ & $26(28.3)$ & & \\
\hline TT & $7(50.0)$ & $11(26.2)$ & & & $36(31.3)$ & $20(21.7)$ & & \\
\hline $\mathrm{CT}$ & $6(42.9)$ & $24(57.1)$ & 0.2072 & & $59(51.3)$ & $46(50.0)$ & 0.1963 & \\
\hline \multicolumn{9}{|c|}{ IL-6 rs1800796 } \\
\hline $\mathrm{C}$ & $20(83.3)$ & $60(71.4)$ & & & $171(73.7)$ & $125(67.9)$ & & \\
\hline G & $4(16.7)$ & $24(28.6)$ & 0.1481 & $4.400(0.511-37.919)$ & $61(26.3)$ & $59(32.1)$ & 0.2861 & $1.387(0.760-2.533)$ \\
\hline $\mathrm{CC}$ & $8(67.7)$ & $21(50.0)$ & & & $61(52.6)$ & $45(48.9)$ & & \\
\hline GG & $0(0.0)$ & $2(4.8)$ & & & $10(8.6)$ & $11(12.0)$ & & \\
\hline CG & $4(33.3)$ & $19(45.2)$ & 0.2931 & & $45(38.8)$ & $36(39.1)$ & 0.5713 & \\
\hline
\end{tabular}

OR, odds ratio; CI, confidence interval; 5-HT2AR, 5-hydroxytryptamine receptor 2A; IL-6, interleukin-6.

of developing OSAHS. Subgroup analysis was performed according to the severity of disease. Allele frequencies of rs6311 were $71.2(\mathrm{~T})$ and $28.8 \%(\mathrm{C})$ in the mild group, and 43.2 (T) and $56.8 \%$ (C) in the moderate group, with evident differences observed between the two groups $(\mathrm{P}=0.0243$; OR, 3.921; 95\% CI, 1.165-13.198). The 'TT' genotype was prevalent in mild patients and ' $\mathrm{CT}$ ' was less frequent in moderate patients $(\mathrm{P}=0.0045)$. Similarity, the ' $\mathrm{CC}$ ', 'TT' and ' $\mathrm{CT}$ ' genotype distributions have differences between the mild and severe cases $(\mathrm{P}=0.0026)$, indicating that the genotype distribution was associated with the severity of OSAHS. However, logistic regression analysis had no statistical difference in the other subgroups (Tables V-VII).

For allele and genotype frequencies of rs1800796 variants, no association was observed (Table IV). Based on the subgroup analysis according to the severity of disease, allele frequencies of rs1800796 were $86.5(\mathrm{C})$ and $13.5 \%(\mathrm{G})$ in the mild group, and 56.8 (C) and $43.2 \%(\mathrm{C})$ in the moderate group, with a significant difference $(\mathrm{P}=0.0064)$. The ' $\mathrm{CC}$ ' genotype was overexpressed in mild, and ' $\mathrm{CG}$ ' and ' $\mathrm{GG}$ ' was more frequent in moderate patients, suggesting that patients with the ' $G$ ' allele were inclined to develop more severe OSAHS $(\mathrm{P}=0.0162)$. There were no statistical differences among the other subgroups (Tables V-VII).

\section{Discussion}

In the present study, the hypothesis of whether the two SNPs (rs6311 in 5-HTR2A and rs1800796 in IL-6) were associated with OSAHS risk in the Chinese Han population was investigated. The results showed that no associations with OSAHS were observed for allele and genotype frequencies in rs6311 
Table VII. Allele and genotype distributions in patients according to the severity of disease.

\begin{tabular}{|c|c|c|c|c|c|c|c|c|c|}
\hline \multirow[b]{2}{*}{ Gene } & \multicolumn{3}{|c|}{ OSAHS, n (\%) } & \multicolumn{2}{|c|}{ Mild versus moderate } & \multicolumn{2}{|c|}{ Mild versus severe } & \multicolumn{2}{|c|}{ Moderate versus severe } \\
\hline & Mild & Moderate & Severe & P-value & OR $(95 \% \mathrm{CI})$ & P-value & OR $(95 \% \mathrm{CI})$ & P-value & OR $(95 \% \mathrm{CI})$ \\
\hline \multicolumn{10}{|c|}{ 5-HTR2A rs6311 } \\
\hline $\mathrm{T}$ & $37(71.2)$ & $19(43.2)$ & $100(62.5)$ & & & & & & \\
\hline $\mathrm{C}$ & $15(28.8)$ & $25(56.8)$ & $60(37.5)$ & 0.0243 & $3.921(1.165-13.198)$ & 0.2746 & $1.717(0.647-4.559)$ & 0.0880 & $0.438(0.167-1.146)$ \\
\hline $\mathrm{CC}$ & 7 (26.9) & $6(27.3)$ & $5(6.2)$ & & & & & & \\
\hline TT & $17(65.4)$ & $2(9.1)$ & $25(31.3)$ & & & & & & \\
\hline $\mathrm{CT}$ & $2(7.7)$ & $14(63.6)$ & $50(62.5)$ & 0.0045 & & 0.0026 & & 0.1137 & \\
\hline \multicolumn{10}{|c|}{ IL-6 rs1800796 } \\
\hline $\mathrm{C}$ & $45(86.5)$ & $25(56.8)$ & $125(78.1)$ & & & & & & \\
\hline $\mathrm{G}$ & $7(13.5)$ & $19(43.2)$ & $35(21.9)$ & 0.0064 & $8.308(1.557-44.321)$ & 0.0587 & $4.000(0.867-18.449)$ & 0.1429 & $0.481(0.179-1.295)$ \\
\hline $\mathrm{CC}$ & $22(84.6)$ & $5(22.7)$ & $47(58.8)$ & & & & & & \\
\hline GG & $0(0.0)$ & $2(9.1)$ & $6(7.5)$ & & & & & & \\
\hline CG & $4(15.4)$ & $15(68.2)$ & $27(33.7)$ & 0.0162 & & 0.1873 & & 0.1928 & \\
\hline
\end{tabular}

OSAHS, obstructive sleep apnea- hypopnea syndrome; OR, odds ratio; CI, confidence interval; 5-HT2AR, 5-hydroxytryptamine receptor $2 \mathrm{~A}$; $I L$ - 6 , interleukin-6.

and rs1800796. However, allele frequencies for rs6311 in male patients had significant differences from the counterparts by gender-specific comparison $(\mathrm{P}=0.0409)$. Additionally, variants of rs6311 and rs1800796 were associated with the severity of OSAHS. There were no significant differences among the other subgroups $(\mathrm{P}>0.05)$.

The variables that promote pharyngeal collapse include negative pressure within the airway and positive pressure outside the airway, increasing the risk of OSAHS. Patency of the human upper airway was maintained mostly by muscle activation. Serotonin has an important role in upper airway dilator muscle activity via modulation of hypoglossal motor output. Therefore, variables that affect serotoninergic activities can lead to sleep and breathing disorders. 5-HTR2A is an essential component of the serotoninergic system, mainly distributed at the hypoglossal motor neurons, and its expression is regulated by $5-H T R 2 A$ genes, located on chromosome 13q14-q21 (16). Therefore, polymorphisms in the 5-HTR2A gene can affect the number of receptors and contribute to OSAHS. Certain studies have been conducted to investigate the association of OSAHS with the polymorphisms of the 5-HTR2A genes with the ' $\mathrm{T}$ ' and ' $\mathrm{C}$ ' allele. Bayazit et al (17) reported on Turkish patients with OSAS, de Carvalho et al (18) reported on Brazilian patients with OSAS, Sakai et al (19) reported on Japanese patients with OSA, and Chen et al (20) and Yin et al (21), reported on Chinese patients with OSAS. All these studies showed that genotypes and allele frequencies of the T102C (rs6311) polymorphism of 5-HTR $2 A$ did not significantly increase the OSAS risk. The present study found that carrying the ' $\mathrm{C}$ ' allele of rs6311 has protection from developing OSAHS in the male population, and genotypes and allele frequency were associated with disease severity. However, the sample size was small, which may increase the chance for spurious findings. In future, larger clinical trials are required to confirm the results.

A previous study revealed that the pathological condition in OSAHS can elevate serum levels of inflammatory cytokines, including tumor necrosis factor- $\alpha$, IL- 6 and IL-18, particularly in the upper airway, resulting in the collapse of the pharyngeal airway (22). Polymorphisms of the gene that influenced inflammation contributed to OSAHS susceptibility. The present study indicated that no differences were observed between patients and control. However, variants of rs1800796 had clear differences between mild and moderate patients, indicating a correlation to OSAHS severity, which has discordance with previous studies. Popko et al (13) confirmed that genotype distribution and allele frequency of the G174C polymorphism in the $I L-6$ gene differed between patients and control, and significant gender differences were also observed regarding the ' $C$ ' and ' $G$ ' alleles of the $I L-6$ genotype in male patients. Kaditis et al (23) reported that the $174 \mathrm{G} / \mathrm{C}$ genetic variation in the $I L-6$ gene was associated with increased risk for OSA in European-Americans. Larkin et al (15) demonstrated that SNP IL-6-6021 contributed to a decreased risk of OSA in African-Americans. These differences were ascribed to the distinct genetic background and the different living environments of the Chinese population compared with other ethnicities. Zhang et al (24) identified that no distribution difference in the $I L-6$ gene was observed between OSAS patients and controls in the Chinese Han population. However, the minor allele 'G' (rs1800796) decreased the risk of OSAS in non-obese subjects, compared with the major allele ' $\mathrm{C}$ ' $(\mathrm{OR}, 0.48$; 95\% CI, 0.26-0.86; $\mathrm{P}=0.014)$. We believe it is primarily attributed to the different definition for overweight or obese patients (BMI $\geq 25 \mathrm{vs} . \geq 27 \mathrm{~kg} / \mathrm{m}^{2}$ ), and in addition, subgroup analysis was not conducted according to the severity of disease in the Zhang et al (24) study.

In conclusion, the present study showed that variants of rs6311 were associated with OSAHS in the male Chinese population. Additionally, the polymorphisms of the 5-HTR2A and $I L-6$ genes were associated with the severity of disease. However, the limitation of the study is that the size is too small to increase the chance for spurious findings.

\section{Acknowledgements}

The authors would like to thank Mr. Wei Cai's team for his excellent technical support. 


\section{References}

1. Peppard PE, Young T, Barnet JH, Palta M, Hagen EW and Hla KM: Increased prevalence of sleep-disordered breathing in adults. Am J Epidemiol 177: 1006-1014, 2013.

2. Palmer LJ, Buxbaum SG, Larkin E, Patel SR, Elston RC, Tishler PV and Redline S: A whole-genome scan for obstructive sleep apnea and obesity. Am J Hum Genet 72: 340-350, 2003.

3. Redline S and Tishler PV: The genetics of sleep apnea. Sleep Med Rev 4: 583-602, 2000.

4. Fenik P and Veasey SC: Pharmacological characterization of serotonergic receptor activity in the hypoglossal nucleus. Am J Respir Crit Care Med 167: 563-569, 2003.

5. Veasey SC: Serotonin agonists and antagonists in obstructive sleep apnea: Therapeutic potential. Am J Respir Med 2: 21-29, 2003

6. Xu H, Guan J, Yi H and Yin S: A systematic review and meta-analysis of the association between serotonergic gene polymorphisms and obstructive sleep apnea syndrome. PLoS One 9: e86460, 2014.

7. Wu Y, Liu HB, Ding M, Liu JN, Zhu XF, Gu JH and Lu G: Association between the $-1438 \mathrm{G} / \mathrm{A}$ and $\mathrm{T} 102 \mathrm{C}$ polymorphisms of 5-HT2A receptor gene and obstructive sleep apnea: A meta-analysis. Mol Biol Rep 40: 6223-6231, 2013.

8. Zhao Y, Tao L, Nie P, Lu X, Xu X, Chen J and Zhu M: Association between 5-HT2A receptor polymorphisms and risk of obstructive sleep apnea and hypopnea syndrome: A systematic review and meta-analysis. Gene 530: 287-294, 2013.

9. Hatipoğlu U and Rubinstein I: Inflammation and obstructive sleep apnea syndrome pathogenesis: A working hypothesis. Respiration 70: 665-671, 2003.

10. Nadeem R, Molnar J, Madbouly EM, Nida M, Aggarwal S, Sajid H, Naseem J and Loomba R: Serum inflammatory markers in obstructive sleep apnea: A meta-analysis. J Clin Sleep Med 9: 1003-1012, 2013.

11. Drummond M, Winck J, Guimarães J, Santos AC, Almeida J and Marques J: Long term effect of autoadjusting positive airway pressure on C-reactive protein and interleukin-6 in men with obstructive sleep apnoea syndrome. Arch Bronconeumol 45: 577-584, 2009 (In Spanish).

12. Kimoff RJ, Hamid Q, Divangahi M, Hussain S, Bao W, Naor N, Payne RJ, Ariyarajah A, Mulrain K and Petrof BJ: Increased upper airway cytokines and oxidative stress in severe obstructive sleep apnoea. Eur Respir J 38: 89-97, 2011.

13. Popko K, Gorska E, Potapinska O, Wasik M, Stoklosa A Plywaczewski R, Winiarska M, Gorecka D, Sliwinski P, Popko M, et al: Frequency of distribution of inflammatory cytokines IL-1, IL- 6 and TNF-alpha gene polymorphism in patients with obstructive sleep apnea. J Physiol Pharmacol 59 (Suppl 6): 607-614, 2008.
14. Burioka N, Miyata M, Fukuoka Y, Endo M and Shimizu E: Day-night variations of serum interleukin-6 in patients with severe obstructive sleep apnea syndrome before and after continuous positive airway pressure (CPAP). Chronobiol Int 25: 827-834, 2008.

15. Larkin EK, Patel SR, Zhu X, Tracy RP, Jenny NS, Reiner AP, Walston J and Redline S: Study of the relationship between the interleukin-6 gene and obstructive sleep apnea. Clin Transl Sci 3: $337-339,2010$.

16. Masuda K, Hashizume C, Ogata N, Kikusui T, Takeuchi Y and Mori Y: Sequencing of canine 5-hydroxytriptamine receptor (5-HTR) 1B, 2A, 2C genes and identification of polymorphisms in the 5-HTR1B gene. J Vet Med Sci 66: 965-972, 2004.

17. Bayazit YA, Yilmaz M, Ciftci T, Erdal E, Kokturk O, Gokdogan T, Kemaloglu YK and Inal E: Association of the $-1438 \mathrm{G} / \mathrm{A}$ polymorphism of the 5-HT2A receptor gene with obstructive sleep apnea syndrome. ORL J Otorhinolaryngol Relat Spec 68: 123-128, 2006

18. de Carvalho TB, Suman M, Molina FD, Piatto VB and Maniglia JV: Relationship of obstructive sleep apnea syndrome with the 5-HT2A receptor gene in Brazilian patients. Sleep Breath 17: 57-62, 2013.

19. Sakai K, Takada T, Nakayama H, Kubota Y, Nakamata M, Satoh M, Suzuki E, Akazawa K and Gejyo F: Serotonin-2A and $2 \mathrm{C}$ receptor gene polymorphisms in Japanese patients with obstructive sleep apnea. Intern Med 44: 928-933, 2005.

20. Chen H, Hu K, Zhu J, Xianyu Y, Cao X, Kang J, He J, Zhao P and Mei Y: Polymorphisms of the 5-hydroxytryptamine 2A/2C receptor genes and 5-hydroxytryptamine transporter gene in Chinese patients with OSAHS. Sleep Breath 17: 1241-1248, 2013.

21. Yin G, Ye J, Han D, Zhang Y, Zeng W and Liang C: Association of the 5-HT2A receptor gene polymorphisms with obstructive sleep apnea hypopnea syndrome in Chinese Han population. Acta Otolaryngol 132: 203-209, 2012.

22. Burioka N, Koyanagi S, Endo M, Takata M, Fukuoka Y, Miyata M, Takeda K, Chikumi H, Ohdo S and Shimizu E: Clock gene dysfunction in patients with obstructive sleep apnoea syndrome. Eur Respir J 32: 105-112, 2008.

23. Kaditis AG, Gozal D, Khalyfa A, Kheirandish-Gozal L, Capdevila OS, Gourgoulianis K, Alexopoulos EI, Chaidas K, Bhattacharjee R, Kim J, et al: Variants in C-reactive protein and IL-6 genes and susceptibility to obstructive sleep apnea in children: A candidate-gene association study in European American and Southeast European populations. Sleep Med 15: 228-235, 2014.

24. Zhang X, Liu RY, Lei Z, Zhu Y, Huang JA, Jiang X, Liu Z, Liu X, Peng $\mathrm{X}, \mathrm{Hu} \mathrm{H}$, et al: Genetic variants in interleukin-6 modified risk of obstructive sleep apnea syndrome. Int J Mol Med 23: 485-493, 2009. 